\title{
The oxidation of hydrocarbons by diverse heterotrophic and mixotrophic bacteria that inhabit deep-sea hydrothermal ecosystems
}

\author{
Wanpeng Wang $\mathbb{1}^{1,2,3} \cdot{\text { Zhenyu } \mathrm{Li}^{1,2,3} \cdot \text { Lingyu Zeng }}^{1,2,3} \cdot$ Chunming Dong ${ }^{1,2,3} \cdot$ Zongze Shao ${ }^{1,2,3}$
}

Received: 22 November 2019 / Revised: 24 March 2020 / Accepted: 15 April 2020 / Published online: 30 April 2020

(c) The Author(s) 2020. This article is published with open access

\begin{abstract}
Hydrothermal activity can generate numerous and diverse hydrocarbon compounds. However, little is known about the influence of such hydrocarbons on deep-sea hydrothermal microbial ecology. We hypothesize that certain bacteria live on these hydrocarbons. Therefore, in this study, the distribution of hydrocarbons and their associated hydrocarbon-degrading bacteria were investigated at deep-sea hydrothermal vents at the Southern Mid-Atlantic Ridge, the Southwest Indian Ridge, and the East Pacific Rise. A variety of hydrocarbon-degrading consortia were obtained from hydrothermal samples collected at the aforementioned sites after low-temperature enrichment under high hydrostatic pressures, and the bacteria responsible for the degradation of hydrocarbons were investigated by DNA-based stable-isotope probing with uniformly ${ }^{13} \mathrm{C}$-labeled hydrocarbons. Unusually, we identified several previously recognized sulfur-oxidizing chemoautotrophs as hydrocarbondegrading bacteria, e.g., the SAR324 group, the SUP05 clade, and Sulfurimonas, and for the first time confirmed their ability to degrade hydrocarbons. In addition, Erythrobacter, Pusillimonas, and SAR202 clade were shown to degrade polycyclic aromatic hydrocarbons for the first time. These results together with relatively high abundance in situ of most of the abovedescribed bacteria highlight the potential influence of hydrocarbons in configuring the vent microbial community, and have made the importance of mixotrophs in hydrothermal vent ecosystems evident.
\end{abstract}

\section{Introduction}

Hydrothermal activity can generate a variety of reduced compounds, including low molecular weight hydrocarbons, which can be produced abiotically through water-rock interactions under high temperature and pressure [1-4]. It was recently discovered that $\mathrm{Fe}^{2+}$ in hydrothermal systems is oxidized by water formed oxygen to give magnetite $\left(\mathrm{Fe}_{3} \mathrm{O}_{4}\right)$,

Supplementary information The online version of this article (https:// doi.org/10.1038/s41396-020-0662-y) contains supplementary material, which is available to authorized users.

Zongze Shao

shaozz@163.com

1 Key Laboratory of Marine Genetic Resources, Third Institute of Oceanography, Ministry of Natural Resources, Xiamen, China

2 State Key Laboratory Breeding Base of Marine Genetic Resources, Third Institute of Oceanography, Xiamen, China

3 Fujian Key Laboratory of Marine Genetic Resources, Xiamen, China while the water is reduced to $\mathrm{H}_{2}$. Ultimately, the $\mathrm{H}_{2}$-dependent reduction of $\mathrm{CO}_{2}$ leads to the generation of hydrocarbons $\left(\mathrm{C}_{2}-\mathrm{C}_{11}\right)$, methane, and aromatics using $\mathrm{Fe}_{3} \mathrm{O}_{4}$ as the catalyst $[5,6]$. Long carbon chain alkanes and polycyclic aromatic hydrocarbons (PAHs) can also be generated in the deep subsurface via thermogenic processes [2, 3, 7, 8]. For instance, numerous hydrocarbons have been observed in the vent fluids and sulfide deposits of the Rainbow vent field at the north Mid-Atlantic Ridge (MAR), including $\mathrm{C}_{9}-\mathrm{C}_{14} n$ alkanes, $\mathrm{C}_{9}-\mathrm{C}_{13}$ branched alkanes, $\mathrm{C}_{9}-\mathrm{C}_{11}$ cycloalkanes, $\mathrm{C}_{7}-\mathrm{C}_{12}$ nonaromatic hydrocarbons, naphthalene, methylnaphthalene, and $\mathrm{C}_{13}-\mathrm{C}_{16}$ PAHs (fluorene, phenanthrene, and pyrene) [1]. Similarly, a high abundance of $n$-alkanes of $\mathrm{C}_{15}-\mathrm{C}_{30}$ chains, and three- or four-ringed PAHs were detected in the hydrothermal sediments from the Lost City vent field at the northern part of the MAR [9].

The deep biosphere may be partially energetically supported by hydrocarbons [10]; however, we know little about this unique ecosystem. Deep-sea hydrothermal vent areas may foster harvesting of deep matter and energy, by unique extremophiles and provide clues to understand the coupling of deepsea life and abiotic and biotic processes under the seafloor. 
Recently, alkane oxidation genes that encode short-chain alkane monooxygenases, degradation pathways for corresponding alcohols, and short-chain fatty acids were found to be abundant in the hydrothermal plume metatranscriptome and metagenome, and these genes may be derived from the uncultivated bacterial group SAR324 [11-13]. In addition, a high diversity of alkane monooxygenases that were phylogenetically affiliated with enzymes involved in $\mathrm{C}_{1}-\mathrm{C}_{4}$ alkane oxidation was observed in the Guaymas Basin hydrothermal plume [14, 15]. Moreover, genes involved in anaerobic hydrocarbon degradation were also detected among several phyla in Guaymas Basin sediments, including Bacteroidetes, Chloroflexi, Deltaproteobacteria, and the candidate phylum Latescibacteria (WS3) [16]. Metagenomic and metatranscriptomic approaches revealed the presence of diverse methylcoenzyme $\mathrm{M}$ reductase-based alkane-oxidizing archaea, including the multi-carbon alkane oxidizer $\mathrm{Ca}$. Syntrophoarchaeum spp., anaerobic methane-oxidizing archaea (ANME-1 and ANME-2c), and sulfate-reducing bacteria (HotSeep-1 and Seep-SRB2) coexisting with sulfate-reducing bacteria and showed the potential for alkane oxidization in Guaymas Basin hydrothermal sediments [17]. However, these advances are mainly based on metadata, while few hydrocarbon-oxidizing microbes have been isolated from deep ecosystems.

In the past decade, we have explored the bacterial diversity involved in PAH degradation in deep-sea sediments of the MAR [18], the west Pacific [19, 20], and the Arctic [21], as well as in the deepwater columns of the southwest Indian Ridge [22].

However, few studies have been conducted within or in the vicinity of the hydrothermal vent field. In the past 10 years, we joined oceanic cruises and collected hydrothermal vent samples from the Southern Mid-Atlantic Ridge, the Southwest Indian Ridge, and the East Pacific Rise to examine the diversity of bacteria that may be driven by hydrocarbons in situ. Here we report the microbial diversity of aliphatic and aromatic hydrocarbons degrading bacteria in the vent plumes, chimney sulfides, and nearby sediments, and confirm their activity under in situ conditions. The results extend the body of knowledge of the potentially hydrocarbon-utilizing microbial community inhabiting the hydrothermal vent ecosystem, and promote understanding of their interactions with extreme environments.

\section{Materials and methods}

\section{Deep-sea sampling, chemicals, and enrichment media}

Samples and their descriptions are provided in Table S1 and Fig. S1 and the Supplementary Materials and Methods.
Detailed descriptions of the chemicals and enrichment media are also described in the Supplementary Materials and Methods.

\section{Hydrocarbon analysis}

To determine the hydrocarbon concentrations in hydrothermal plume samples, a method that combined stir bar sorptive extraction, thermal desorption-gas chromatography-mass spectrometry, and the Hydro-CARB ${ }^{\circledR}$ software package (IFP, Rueil-Malmaison, France) was used. The details of these procedures are described in the Supplementary Materials and Methods.

\section{Enrichment of hydrocarbon-degrading bacteria at high pressure}

Deep-sea-mimicking cultivation was conducted under high pressures and low temperatures in the chamber of a HP vessel as described in the Supplementary Materials and Methods.

\section{Stable-isotope probing experiments}

Stable-isotope probing (SIP) experiments for the above plume, sulfide deposit, and sediment enrichments were performed with ${ }^{13} \mathrm{C}$-labeled alkanes and PAHs, yielding a total of 12 samples. The details of these procedures are described in the Supplementary Materials and Methods.

\section{Isolation of heterotrophic hydrocarbon-degrading bacteria}

Serial dilutions of enrichments were streaked onto M2 agar plates, then incubated at $15^{\circ} \mathrm{C}$ until the formation of bacterial colonies was observed. Colonies exhibiting unique morphological features were selected and re-streaked onto M2 plates to obtain pure cultures that were then preserved at $-20{ }^{\circ} \mathrm{C}$ for further analyses.

\section{Cultivation and isolation of chemoautotrophs from hydrocarbon-degrading consortia}

Cultures and isolates were identified as previously described [23, 24], with slight modifications. The details of these procedures are described in the Supplementary Materials and Methods.

\section{Hydrocarbon degradation by consortia and isolates under high hydrostatic pressures and low temperature}

The hydrocarbon degradation procedures are described in detail in the Supplementary Materials and Methods. 


\section{Analysis of bacterial community structures}

A detailed description of the analysis of bacterial community structures procedures is described in the Supplementary Materials and Methods.

\section{Nucleotide sequence availability}

All of the Illumina sequence data from this study were submitted to the NCBI Sequence Read Archive under accession numbers SRR067098 and SRR1006106310061075. Sanger-sequenced 16S rDNA sequences from the isolates were submitted to GenBank under accession numbers KT581452-KT581573, KT596765-KT596769, and MT084040-MT084046.

\section{Results}

\section{Hydrocarbons in deep-sea hydrothermal field samples}

The concentration and composition of hydrocarbons were measured in the samples from hydrothermal fields at the southern Mid-Atlantic Ridge (SMAR), southwest Indian Ridge (SWIR), and East Pacific Rise (EPR), and in vent plumes, sulfide chimney samples, and sediments (Table S2). In the five plume samples from SMAR, the total hydrocarbon concentrations (THC) ranged from 462.6 to $742.1 \mu \mathrm{g} \cdot \mathrm{L}^{-1}$ (Fig. 1a). In contrast, THC in the nearby non-plume deep-sea water was only $10.3 \mu \mathrm{g} \cdot \mathrm{L}^{-1}$ (Table S2). In the chimney sulfide samples, THCs were present at concentrations of 17.1, 15.3, and $13.2 \mu \mathrm{g} \cdot \mathrm{g}^{-1}$ (dry weight) in the SMAR, EPR, and SWIR samples, respectively (Table S2), with PAHs, $n$-alkanes $\left(\mathrm{C}_{14}-\mathrm{C}_{28}\right)$, and branched alkanes $\left(\mathrm{C}_{16}-\mathrm{C}_{20}\right)$ as the major components (Fig. 1b). In the hydrothermal sediments, the THCs ranged from 2.9 to $3.9 \mu \mathrm{g} \cdot \mathrm{g}^{-1}$ (dry weight), with high concentrations of polycyclic aromatic hydrocarbons containing $2-5$ rings detected in all of the sediment samples; however, only a few types of alkanes were detected, and these were present at low concentrations (Fig. 1c and Table S2).

\section{Bacterial diversity in the hydrothermal plume in situ}

The bacterial community composition of the plume samples of the newly discovered hydrothermal field named Deyin-1 on the south MAR $\left(15^{\circ} \mathrm{S}\right)$ is shown in Fig. 2. In the rising plume sample (SAP-1_S), the 16S rRNA gene sequences related to gamma-proteobacteria $(31.5 \%)$ and epsilonproteobacteria (19.2\%) were highly abundant (Fig. 2). Among the detected gamma-proteobacteria, levels of the following genera were relatively high Alcanivorax (7.4\% of the total), Glaciecola (6.7\%), Marinobacter (3.7\%), SUP05 clade sequences (3.7\%), Cycloclasticus (2.3\%), and Alteromonas (1.8\%) (Fig. 2). Among the epsilon-proteobacteria sequences, the genera Sulfurimonas (11.9\%), Sulfurovum (4.9\%), and Arcobacter (2.1\%) were present at relatively high concentrations (Fig. 2a). Additionally, the SAR324 clade $(4.4 \%)$ of delta-proteobacteria and the SAR202 clade (3.2\%) of Chloroflexi were detected in the rising plume sample (Fig. 2).

In the two neutrally buoyant plume samples (SAP-2_S to 5_S), which were collected far from the vent compared with the samples described above, the sequence reads mainly corresponded to gamma-proteobacteria (34.3-47.2\%), epsilonproteobacteria (5-8.8\%), and alpha-proteobacteria (8.1-10.3\%) (Fig. 2). The abundance of epsilon-proteobacteria decreased and alpha-proteobacteria appeared. The gamma-proteobacteria were mainly composed of Alcanivorax (9.2-10.3\%), Cycloclasticus (2.2-3.9\%), Glaciecola (5.1-11.4\%), Marinobacter (2.2-3.1\%), the SUP05 clade (0.6-2.2\%), and Alteromonas (0.6-3.2\%), among which the first two are well known for alkane and PAHs degradation. The epsilon-proteobacteria mainly were mainly composed of Sulfurimonas (3.5-6.8\%), Sulfurovum (0.3-1.6\%), and Arcobacter (0.9-1.8\%). Notably, the genus Erythrobacter of alpha-proteobacteria also occurred as a dominant member, accounting for $6.6-8.5 \%$ of the total bacterial $16 \mathrm{~S}$ rRNA gene sequences. In addition, clade SAR324 of delta-proteobacteria and clade SAR202 of Chloroflexi also occurred as the dominant bacteria in situ, comprising $4.1-5.8 \%$ and $0.9-1.7 \%$ of the total $16 \mathrm{~S}$ rRNA sequence reads, respectively.

\section{Hydrocarbon biodegradation in the hydrothermal plume}

To confirm the bacteria were utilizing hydrocarbons from the hydrothermal plumes, enrichment with a mixture of $n$ alkanes and PAHs as the carbon and energy sources was conducted while mimicking the deep-sea conditions of high static pressure and low temperature. Quantification showed that both alkanes and PAHs could be degraded significantly by the five plume-derived enrichment consortia (SAP-1 to SAP-5) under $20 \mathrm{MPa}$ and at $10^{\circ} \mathrm{C}$. Specifically, nearly all $n$-alkanes were removed after 60 days, with the degradation percentages of $91.7-96.5 \%$ (Table S3), while $74.6-84.1 \%$ of the total PAHs were removed (Table S3).

Further, bacteria capable of hydrocarbon degradation were retrieved by SIP-sequencing. Four genera of bacteria were enriched with alkanes and the PAHs mixture as follows: Alcanivorax (14.1-22.3\%), Marinobacter (7.9-13.1\%), Cycloclasticus (9.4-14.3\%), and Erythrobacter (7.7-13.7\%) (Fig. 2). Unexpectedly, the previously recognized chemoautotrophic bacteria were also retained in all of the SIP com- 
Fig. 1 Hydrocarbon concentrations in deep-sea hydrothermal samples. Hydrothermal vent plume samples (a); hydrothermal chimney samples (b); hydrothermal sediment samples (c). Data are the means of three independent measurements.

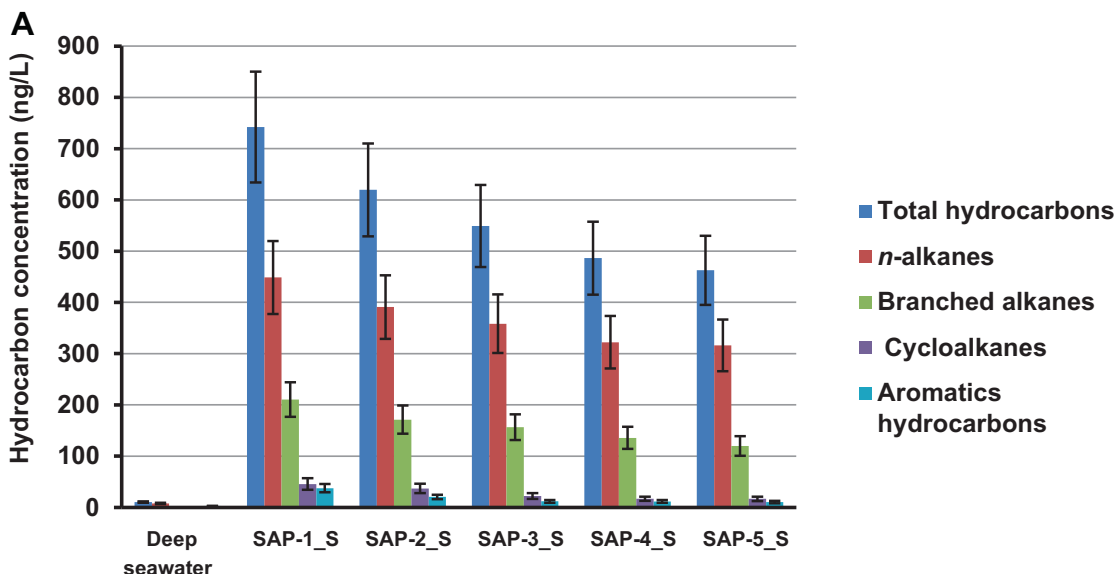

B
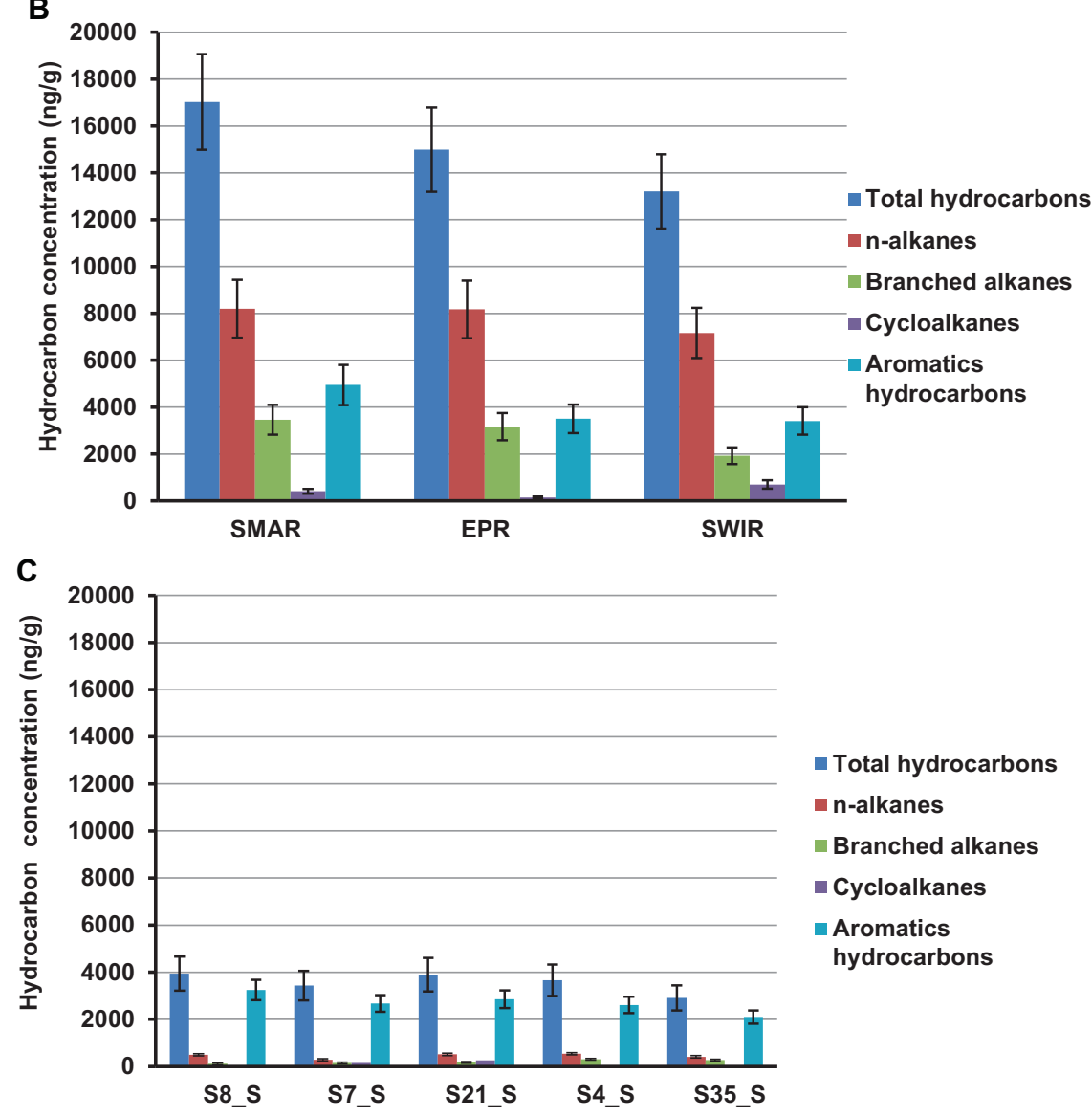

- Total hydrocarbons

n-alkanes

Branched alkanes

- Cycloalkanes

Aromatics

hydrocarbons munities, including the genus Sulfurimonas and the SUP05 and SAR324 clades.

\section{Bacterial diversity in hydrothermal chimneys}

The detailed bacterial diversity of black smoker chimney samples collected from three active hydrothermal fields in the SWIR, SMAR, and EPR are shown in Fig. 3.
Despite the great geographic distance, the bacterial compositions at the three sites were similar, being mainly composed of Sulfurovum, Sulfurimonas, Thiomicrospira, Nitrospira, Desulfurobacterium, Thermodesulfatator, Desulfobulbus, Pseudoalteromonas, Marinicella, Gallionella, Marinobacter, Halomonas, and Alcanivorax, although they did vary to some extent. Additionally, the SAR202 clade was prevalent the indigenous consortia of all three sulfide chimneys. 


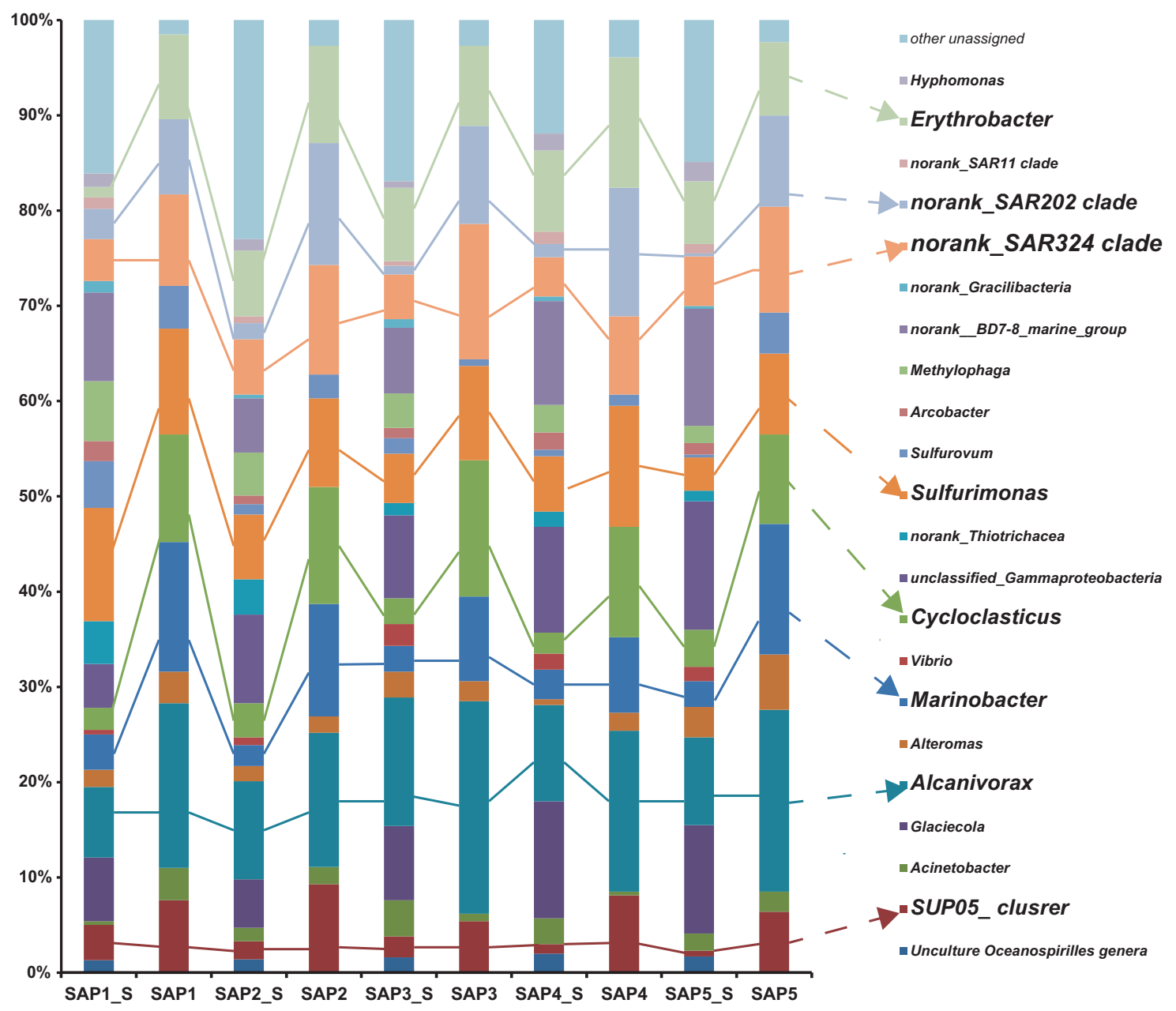

Fig. 2 Taxonomic distribution among the five hydrothermal vent plume indigenous consortia (SAP1_S to SAP5_S) and hydrocarbon-enrichment SIP consortia (SAP1 to SAP5). Only

\section{Hydrocarbon-degrading bacteria from the hydrothermal chimneys}

To identify the hydrocarbon-degrading microbes inhabiting the hydrothermal chimneys, enrichment with a hydrocarbon mixture was conducted under hydrostatic pressures (20-35 MPa) and $10{ }^{\circ} \mathrm{C}$ according to the water depths and in situ temperatures, after which the hydrocarbon biodegradation capability of the hydrothermal chimney-derived consortia was tested. Within 20 days, $55-66 \%$ of the total $n$-alkanes and $20-35 \%$ of the total PAHs had been degraded. At day 40, 77-89\% of the total $n$ alkanes and $44-52 \%$ of the total PAHs had been degraded, while at day $60,92-97 \%$ of the total $n$-alkanes and $76-78 \%$ of the total PAHs had been degraded (Table S4). To define what types of bacteria in hydrothermal chimneys were hydrocarbon degraders, SIP-Seq data analysis was conducted after enrichment with ${ }^{13} \mathrm{C}$-labeled hydrocarbons for 60 days under $30 \mathrm{MPa}$ at $10{ }^{\circ} \mathrm{C}$. The results revealed that the SIP community mainly genera that represent $>3 \%$ of the communities in at least one sample are indicated. The "unassigned" categories represent all of the groups comprising $<3 \%$ of the communities.

contained the following genera: Marinobacter (27.7-36.3\%), Sulfurimonas (14.1-17.7\%), Halomonas (5.2-24.3\%), and Pseudoalteromonas (7.3-9.6\%), as well as bacteria of clade SAR202 (6.2-10.4\%) and clade SAR324 (3.1-12.3\%). Among these, Marinobacter had the highest abundance, followed by Sulfurimonas and Halomonas. Congruent with the in situ diversity, despite the large geographic distance, quite similar degrading bacterial communities were obtained from the three global ocean hydrothermal chimney samples. Detailed compositions of the above hydrocarbon-degrading consortia are shown in Fig. 3.

\section{Bacterial diversity in hydrothermal sediments}

Bacterial compositions of the five hydrothermal sediment samples collected from the SWIR, SMAR, and EPR sites are shown in Fig. 4. The following bacteria were characterized as the dominant members in the five sediments based on their $16 \mathrm{~S}$ 
Fig. 3 Taxonomic distribution among the three hydrothermal chimney indigenous consortia (SAMR, SWIR, and EPR) and hydrocarbon-enrichment SIP consortia (SAHCS, WSIP, and EPHCS). Only genera that represented $>3 \%$ of the communities in at least one sample are indicated. The "unassigned" categories represented all of the groups comprising $<3 \%$ of the communities.

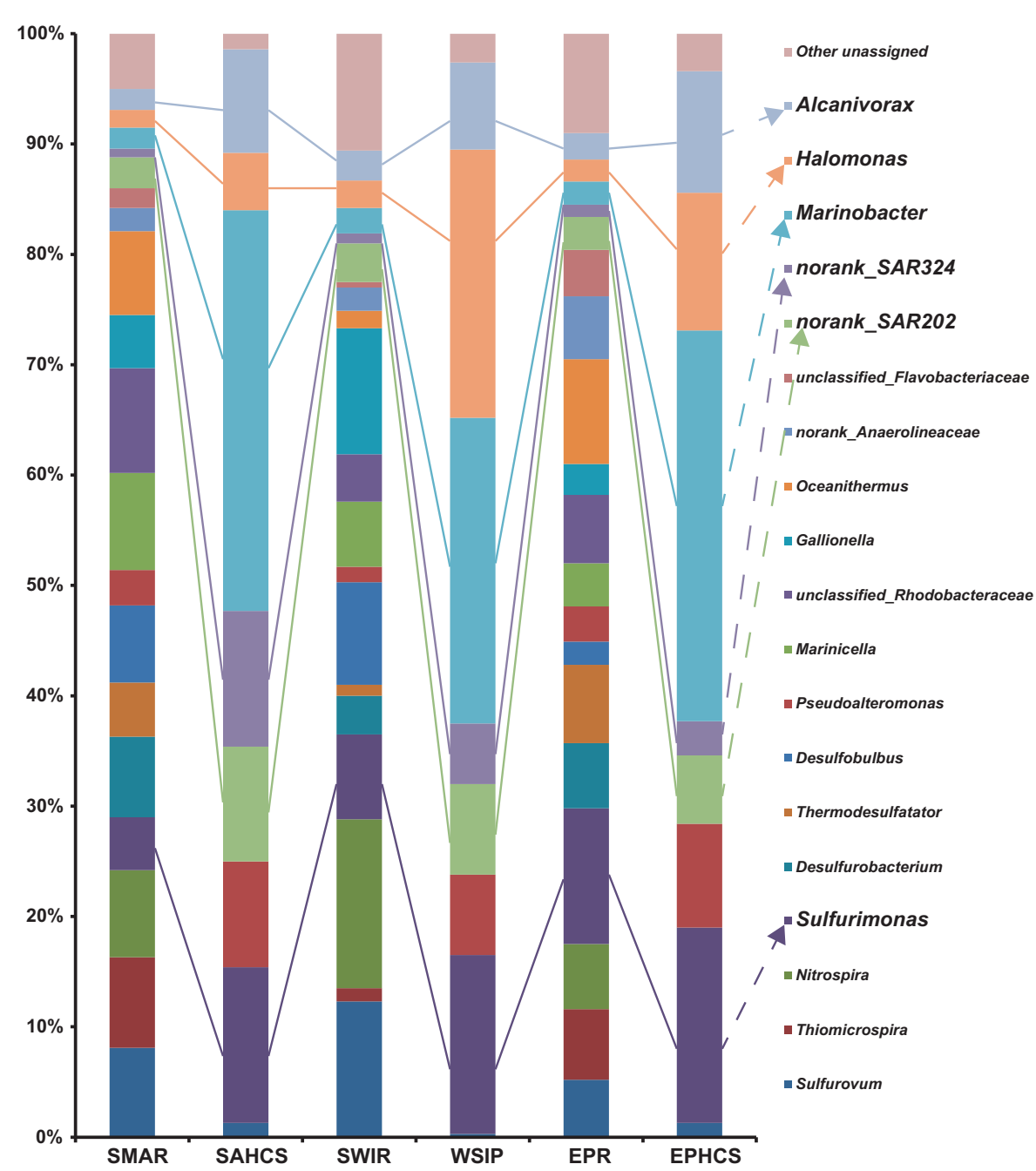

rRNA gene abundance: Nitrospira (6.3-9.1\%), Erythrobacter (1.8-4.9\%), Burkholderia (2.3-9.3\%), Alcanivorax (1.4-3.9\%), Marinobacter (1.5-3.4\%), Rhodococcus (0.5-3.5\%), Halomonas (1.3-3.2\%), Pseudomonas (0.7-3.9\%), Pusillimonas (0.5-3.5\%), Acinetobacter (0.6-1.8\%), and the SAR202 clade (0.7-2.7\%) (Fig. 4). In addition, the bacterial no-rank OM1 clade, S085 clade, JG30-KF-CM66 clade, Acidobacteria, Anaerolineaceae, Hyphomicrobiaceae, Rhodospirillaceae, Aminicenantes, Gemmatimonadetes, Gemmatimonadaceae, and unclassified gamma-proteobacteria frequently occurred in different sediment samples (Fig. 4).

\section{Bacterial PAHs biodegradation in hydrothermal sediments}

All five hydrothermal sediment consortia enriched with PAHs showed obvious degradation activity under $35 \mathrm{MPa}$ and at 10 ${ }^{\circ} \mathrm{C}$ (Table S5). In addition, all five types of added PAHs of 2-5 rings were significantly degraded. At day 90, naphthalene was totally degraded, while $82-89 \%$ of fluoranthene, $87-91 \%$ of phenanthrene, $80-94 \%$ of pyrene, and $38-50 \%$ of benzo[a] pyrene was degraded (Table S5).

To identify the key PAH degraders among the associated bacteria, the above SIP samples were enriched with the PAH mixture for 90 days under $35 \mathrm{MPa}$ and $10^{\circ} \mathrm{C}$, then further processed by SIP-Seq. The results revealed nine bacterial genera were retained as ${ }^{13} \mathrm{C}$-labeled bacterial members in all degradation communities of the five sediment samples; namely, Erythrobacter, Halomonas, the SAR202 clade, Alcanivorax, Marinobacter, Burkholderia, Pseudomonas, Pusillimonas, and Rhodococcus (Fig. 4). However, the abundance of these organisms varied among samples, with the first four being the most abundant members. Nevertheless, these labeled bacteria were all suggested to be key PAH degraders, such as Pusillimonas and Rhodococcus in the two SWIR consortia S7 and S8 and Marinobacter in consortium SMAR (S21) and EPR (S35). 
Fig. 4 Taxonomic distribution among the five hydrothermal sediment indigenous consortia (S4_S, S7_S, S8_S, S21_S, and S35_S) and PAH-enrichment SIP consortia (S4, S7, S8, S21, and S35). Only genera that represent $>3 \%$ of the communities in at least one sample are indicated. The "unassigned" categories represent all of the groups comprising $<3 \%$ of the communities.

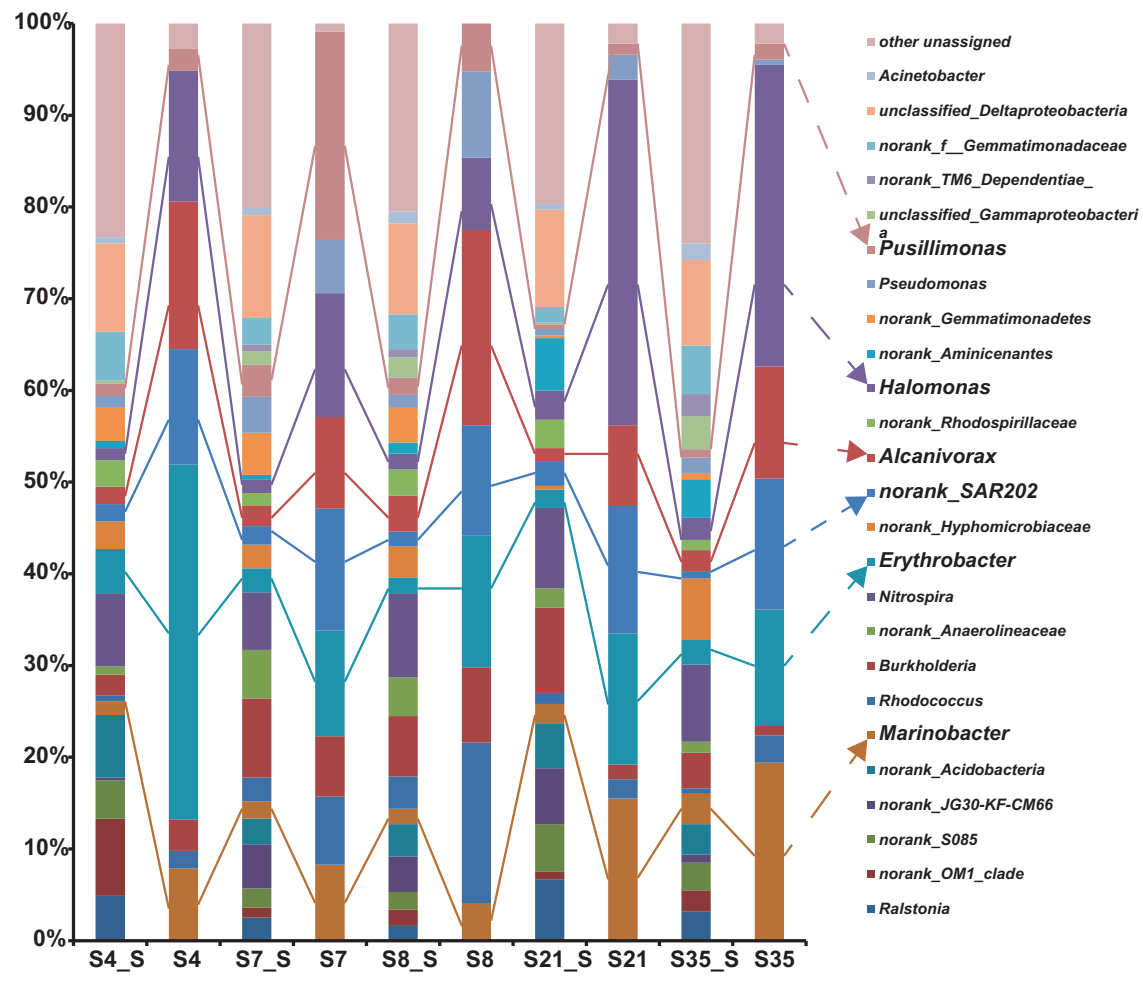

\section{Isolation of chemoautotrophs from enrichment cultures}

The once recognized chemoautotrophic bacteria, including the SAR324 clade, SUP05 clade, and Sulfurimonas, occurred as dominant members of the above hydrocarbondegrading consortia of vent plumes and sulfides, and were confirmed by SIP-Seq. To better characterize their roles, further enrichment and pure culture isolation and further testing were conducted to determine their potential for hydrocarbon degradation. Thirty-seven out of 1536 culture wells from the above hydrothermal plume and chimney hydrocarbon enrichments were positive for growth, with sulfur oxidation occurring after 21 days. Moreover, four of the cultures had identical 16S rRNA gene sequences and were identified as members of Sulfurimonas, named strain Sulfurimonas sp. hwp1, hwp2, hwp3, and hwp4 (Fig. 5). Two cultures were identified as a delta-proteobacteria related to the SAR324 group, and named SAR324 strain hwp5 and strain hwp6 (Fig. 6). In addition, one culture was identified as a member of the SUP05 clade, named SUP05 strain hwp7 (Fig. 7).

\section{Hydrocarbon degradation by chemolithoautotrophs}

The hydrocarbon degradation potential of pure cultures of Sulfurimonas spp., and the SAR324 and SUP05 clades were evaluated further under high HPs and low temperatures using hydrocarbon as the sole carbon and energy sources (adequate $\mathrm{O}_{2}$, remove $\mathrm{CO}_{2}$ and thiosulfate). All four isolates of Sulfurimonas and two isolates of SAR324 that were tested exhibited vigorous growth in the short chain length alkane assays using ${ }^{13} \mathrm{C}$-labeled $n$-hexane and $n$-octane under high HPs and low temperatures (Table 1 and Fig. S2). In addition, they also exhibited growth in the medium chain length alkanes of ${ }^{13} \mathrm{C}$-labeled $n$-decane and $n$-dodecane under high pressure and low temperature, but this was comparatively weak (Table 1 and Fig. S2). Only the isolates of SAR324 (strain hwp5 and hwp6) exhibited weak growth in the ${ }^{13} \mathrm{C}$-labeled $n$-hexadecane (Table 1 and Fig. S2). All four Sulfurimonas isolates exhibited weak growth under high HPs and low temperatures in the PAH assays using ${ }^{13} \mathrm{C}$-labeled naphthalene and phenanthrene, respectively (Table 1 and Fig. S2). None of the isolates grew with $n$ tetracosane, pyrene, or benzo(a)pyrene (Table 1). None of all tested hydrocarbons could be utilized by isolate hwp7 of SUP05 (Table 1).

All four Sulfurimonas isolates exhibited hydrocarbon degradation and degrade $n$-alkanes of $\mathrm{C}_{6}-\mathrm{C}_{16}$ as well as naphthalene and phenanthrene (Table 1). These phylotypes were closely related to the predominant members $(>99.7 \%$ homology with $450 \mathrm{bps} 16 \mathrm{~S}$ rRNA) in plumes and sulfides in situ as well as those in the hydrocarbon-degrading consortia. Based on the OTU sequences and our isolates, a phylogenetic tree was constructed with references of the type strains (Fig. 5). The results showed that the four isolates were affiliated with four species, among which strain hwp4 isolated from the chimney of the new hydrothermal 


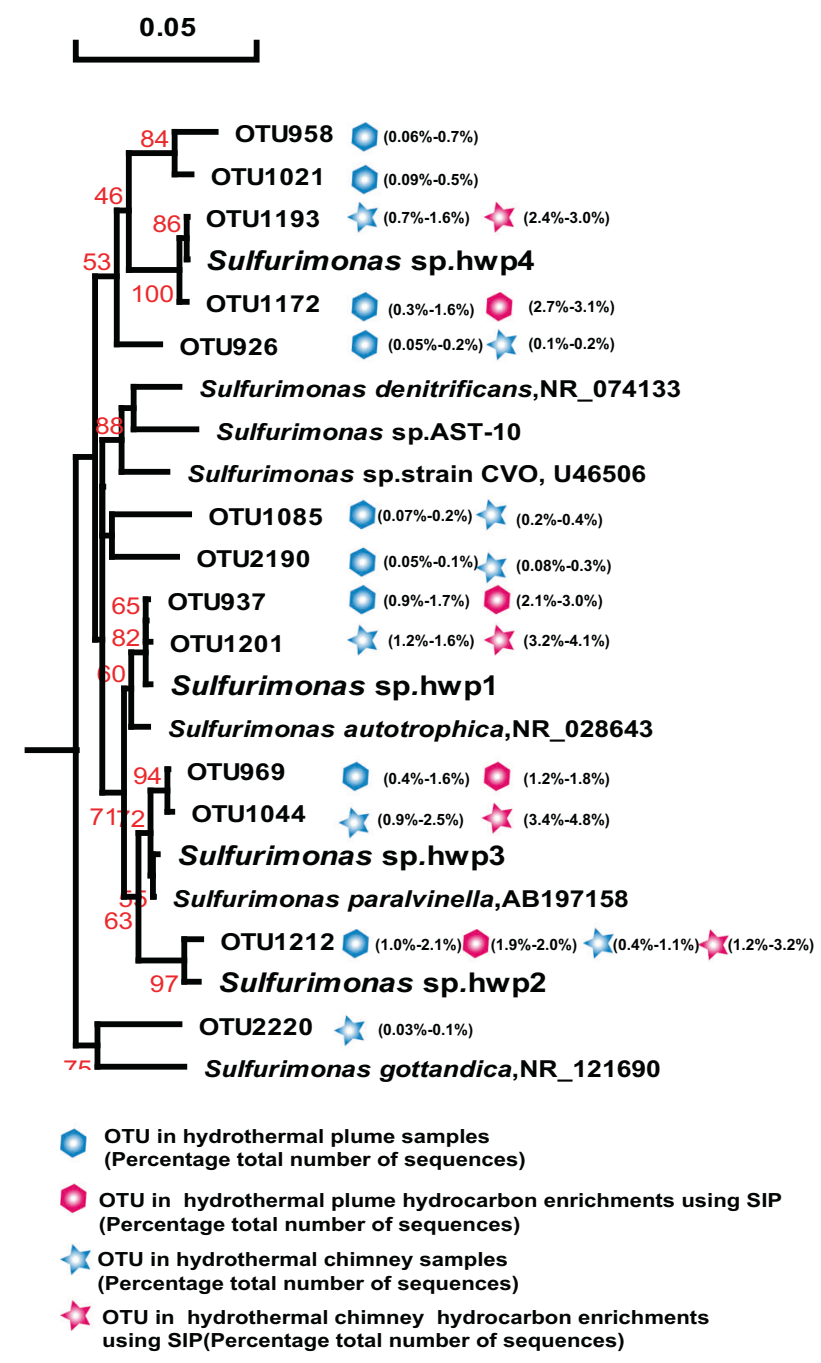

Fig. 5 Sulfurimonas distribution among consortia and phylogenetic analysis of 16S rRNA gene phylotypes. Phylogenetic tree showing the diversity of 16S rRNA gene sequences from OTUs and isolates of Sulfurimonas identified in this study. The tree was constructed using neighbor-joining methods and the Kimura 2-parameter model, as implemented in the MEGA 5.0 software package. The tree is based on partial 16S rRNA gene sequences from this study and their closest type strains. Only bootstrap values $\geq 50 \%$ (based on 1000 bootstrap replicates) are shown at the nodes. The scale bar represents 0.05 nucleotide changes per site. Sulfurimonas OTU distribution among the different hydrocarbon-enrichment consortia and indigenous consortia. Only OTUs representing $>1 \%$ of the communities in at least one sample are included in the visualization. OTU representative sequences are shown in the Supplementary Information.

field Deyin in the southern MAR represented a novel species forming a separate cluster with the homologue OTU1193 from the same chimney sample and OTU1172 from the plume also located at Deyin (pink in Fig. 5), in addition to other members identified in situ (labeled blue). Moreover, strain hwp2 represented a novel species with $96.6 \%$ homology to the full-length $16 \mathrm{~S}$ of Sulfurimonas paralvinella, whereas the strain hwp3 and hwp4 belonged to Sulfurimonas autotrophica and S. paralvinella, respectively.
0.05

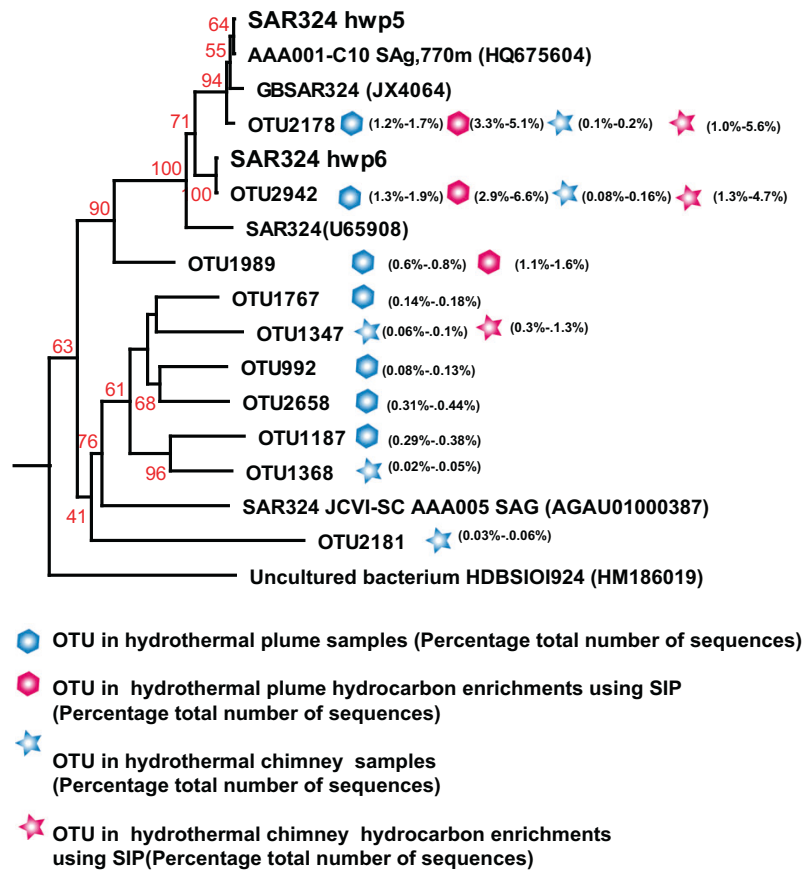

Fig. 6 SAR324 distribution among consortia and phylogenetic analysis of 16S rRNA gene phylotypes. Phylogenetic tree showing the diversity of $16 \mathrm{~S}$ rRNA gene sequences from OTUs and isolates of SAR324 identified in this study. The tree was constructed using neighbor-joining methods and the Kimura 2-parameter model, as implemented in the MEGA 5.0 software package. The tree is based on partial 16S rRNA gene sequences from this study and their closest type strains. Only bootstrap values $\geq 50 \%$ (based on 1000 bootstrap replicates) are shown at the nodes. The scale bar represents 0.05 nucleotide changes per site. SAR324 OTU distribution among the different hydrocarbon-enrichment consortia and indigenous consortia. Only OTUs representing $>1 \%$ of the communities in at least one sample are included in the visualization. OTU representative sequences are shown in the Supplementary Information.

Despite the significant divergence in phylogeny, all four isolates possessed the same characteristics with respect to hydrocarbon utilization.

Similarly, SAR324 isolates hwp5 and hwp6 also exhibited positive alkane degradation (Table 1). Both were isolated from the Deyin field plume and shared 97.85\% homology of the 16S rRNA gene, representing two potential novel species. A phylogenetic tree was constructed based on the 16S rRNA gene sequences of this study and the other four sequences retrieved from GenBank (Fig. 6). The phylogenetic result showed that this group in our study samples was quite diverse. The two isolates correspond to the predominant members represented by OTU2178 in the MAR plume and OTU2943 in the MAR sulfides and hydrocarbon-degrading consortia, respectively (Fig. 6). Among the tested $n$-alkanes from $\mathrm{C}_{6}$ to $\mathrm{C}_{32}$, both isolates could grow with $n$-hexane, octane, decane, dodecane, and hexadecane (Table 1), while they failed to grow with all 


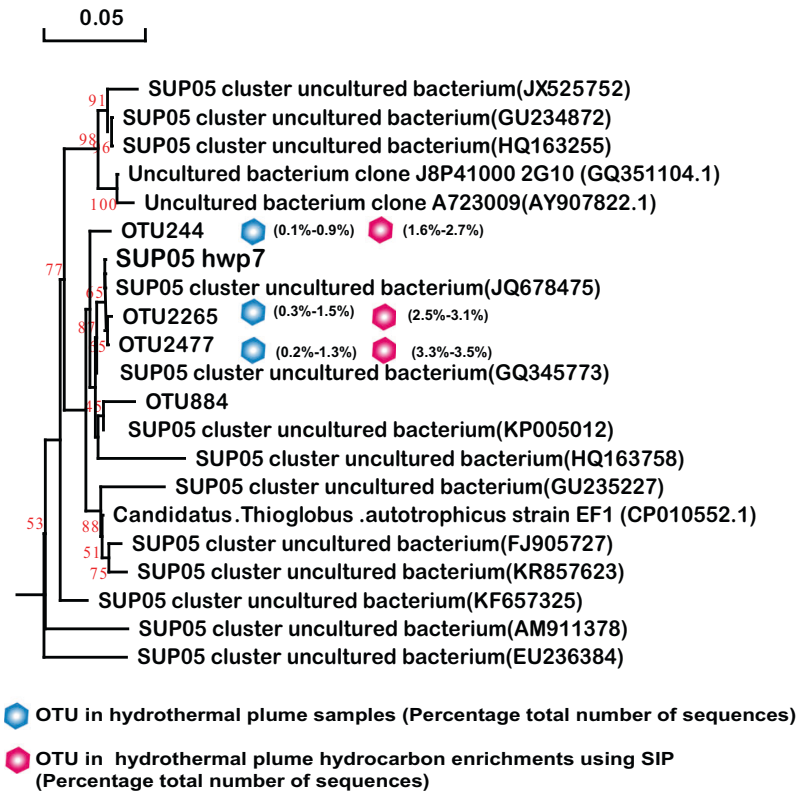

Fig. 7 SUP05 distribution among consortia and phylogenetic analysis of $16 \mathrm{~S}$ rRNA gene phylotypes. Phylogenetic tree showing the diversity of 16S rRNA gene sequences from OTUs and isolates of SUP05 identified in this study. The tree was constructed using neighbor-joining methods and the Kimura 2-parameter model, as implemented in the MEGA 5.0 software package. The tree is based on partial 16S rRNA gene sequences from this study and their closest type strains. Only bootstrap values $\geq 50 \%$ (based on 1000 bootstrap replicates) are shown at the nodes. The scale bar represents 0.05 nucleotide changes per site. SUP05 OTU distribution among the different hydrocarbon-enrichment consortia and indigenous consortia. Only OTUs representing $>1 \%$ of the communities in at least one sample are included in the visualization. OTU representative sequences are shown in the Supplementary Information.

tested odd alkanes of $\mathrm{C}_{11}, \mathrm{C}_{15}$, and $\mathrm{C}_{17}$, or with long-chain $n$-alkanes above $\mathrm{C}_{20}$ (data not shown). These isolates could not grow with any tested PAHs either (Table 1). Interestingly, SUP05 isolate hwp7 was closely related to the predominant members in plumes in situ, as well as the hydrocarbon-enrichment consortia, represented by OTU2265 and OTU2477 (Fig. 7); however, this organism was negative for hydrocarbon degradation (Table 1). Our isolate hwp7 together with other OTUs formed an independent cluster in the tree, neighboring with the cluster represented by the previously reported isolate Candidatus Thioglobus autotrophicus strain EF1 (Fig. 7). The two isolates showed $97.5 \%$ identity in the full-length $16 \mathrm{~S}$ rRNA gene sequence, indicating they represent two potential novel species of the genus Thioglobus.

\section{Hydrocarbon degradation by heterotrophic isolates under high pressures}

A total of 126 heterotrophic strains were isolated from the above hydrocarbon-enrichment consortia, and most could

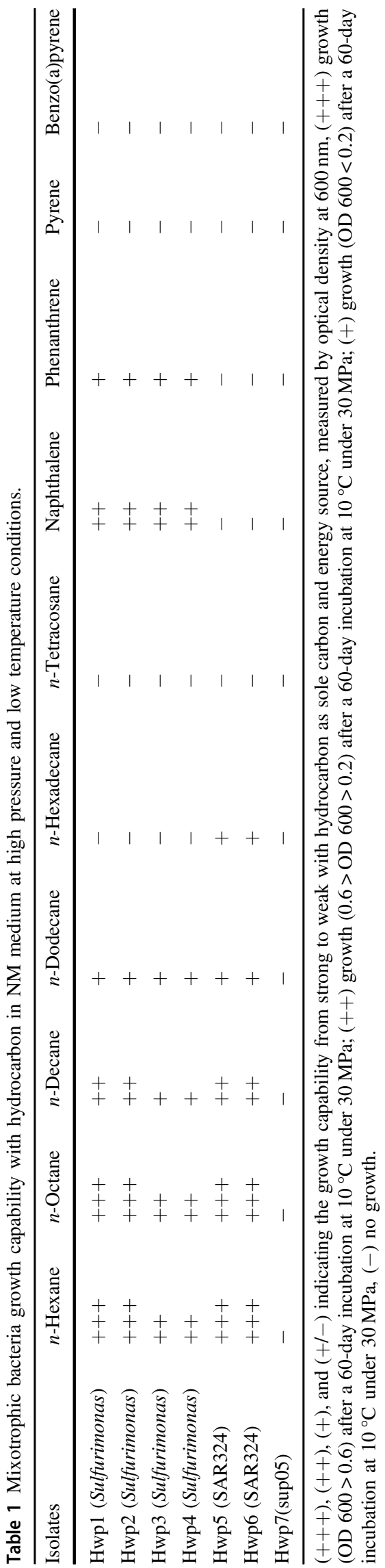


grow with hexadecane or PAH as the sole carbon and energy source. These organisms were affiliated with 16 genera, including Alcanivorax, Acinetobacter, Alteromonas, Bacillus, Citreicella, Dietzia, Erythrobacter, Halomonas, Idiomarina, Marinobacter, Microbacterium, Novosphingobium, Sphingobium, Pseudomonas, Pusillimonas, and Spongibacter (Table S6).

Thirteen of the isolates could grow with ${ }^{13} \mathrm{C}$-labeled $n$-hexadecane as the sole energy source under $35 \mathrm{MPa}$ at $10{ }^{\circ} \mathrm{C}$ as determined by cell density $\mathrm{OD}_{600}$ (Fig. S3B), and the degradation was confirmed by quantification using the ${ }^{13} \mathrm{C}$ isotope (Fig. S3A). Based on their $16 \mathrm{~S}$ rRNA sequences, these isolates were identified as Alcanivorax dieselole $i$ strain S19-9, Alcanivorax sp. strain YLF38, Alcanivorax venustensis strain RY-9, Bacillus safensis strain S21-L1, Halomonas titanicae strain RY-7, Marinobacter bryozoorum strain TG8-3, Marinobacter hydrocarbonoclasticus strain S19-1, Marinobacter segnicrescens strain S19-13, Marinobacter vinifirmus strain S19-10, Oceanicola marinus strain 22F16, Oceanicola nanhaiensis strain 1F26, Rhodococcus yunnanensis strain YLF8, and Pusillimonas sp. strain S7-N8 (Fig. S3A, B).

In the PAH assays, eight isolates exhibited noticeable growth under high HP and low temperature within 60 days based on ${ }^{13} \mathrm{C}_{6}$-labeled phenanthrene analysis (Fig. S3C), while significant degradation occurred within 120 days under the same conditions (Fig. S3D). These isolates were identified and named as Erythrobacter sp. strain S35-N8, Erythrobacter sp. strain S21-N3, Pusillimonas sp. strain S7N8, E. flavus Y strain LF25, Marinobacter algicola strain YLF36, M. hydrocarbonoclasticus strain S19-1, B. safensis strain S21-L1, and B. safensis strain S8-L9.

Interestingly, Erythrobacter sp. S21-N3 and Pusillimonas sp. S7-N8 exhibited vigorous growth using various PAHs including naphthalene- $-{ }^{13} \mathrm{C}_{6}$, phenanthrene- ${ }^{13} \mathrm{C}_{6}$, pyrene${ }^{13} \mathrm{C}_{6}$, fluorene- $-{ }^{13} \mathrm{C}_{6}$, and benzo[ $[\alpha]$ pyrene- $-{ }^{13} \mathrm{C}_{6}$ (Figs. S3E, F, and $\mathrm{S} 4)$.

\section{Discussion}

Previous studies of microbial vent communities have mainly focused on chemolithoautotrophic organisms. These studies have shown that chemoautotrophic bacteria such as Sulfurimonas and clades of SAR324 and SUP05 were ubiquitous in the global deep-sea hydrothermal ecosystem and commonly recognized as the sulfur-oxidizing chemolithoautotrophs responsible for to the primary production of vent ecosystems. Although various hydrocarbons can be generated from the deep subsurface processes, little is known about their contribution to the determination of vent bacterial diversity. During our investigation, it is quite unexpected to find that fundamental chemoautotrophs such as Sulfurimonas and the SAR324 clade were capable of degrading hydrocarbons and active under simulated extreme conditions.

Interestingly, although the bacteria of the SUP05 clade were dominant members of all of the plume-derived hydrocarbon-degrading consortia, the purified isolate (strain hwp7) failed to degrade any tested hydrocarbons. However, genome analysis showed that the strain hwp7 genome harbored multiple genes encoding enzymes involved in aromatic or alkane carbon catabolism, including proteins with predicted functions in aromatic ring hydroxylation, alicyclic rings oxidation, catechol degradation, phenylpropionate degradation, fatty aldehydes oxidation, and fatty carboxylic acids oxidation (data not shown). Because it can grow without nutrient supplements such as vitamins and amino acids in medium of thiosulfate oxidization, we speculate that the SUP05 strain hwp7 may utilize the intermediate metabolites of hydrocarbons of other bacteria instead of via syntrophism.

The SAR324 group of delta-proteobacteria is ubiquitous in global oceans [14], and is one of the most abundant microbial groups in deep-sea hydrothermal plumes [15, 25]. To date, none of the bacteria comprising this group have been isolated, although it is well known as a sulfuroxidizing bacterium [14]. Recently, metagenomic and metatranscriptomic analyses showed that the particulate hydrocarbon monooxygenase (pHMO), which is believed to be responsible for oxidizing short-chain alkanes of $\mathrm{C}_{2}-\mathrm{C}_{4}$, is present and expressed in the Guaymas Basin hydrothermal plume [11]. In the present, SAR324 not only occurred as one of the most abundant bacteria in situ, but also constituted the majority of the hydrocarbon SIP consortia from hydrothermal plumes and chimneys. Notably, two SAR324 isolates numbered hwp5 and hwp6 were isolated and 16S rRNA genes showed high similarity (98.8 and 98.3\%) to SAR324 from the Guaymas Basin hydrothermal plume. Moreover, they both exhibited degradation activity on $n$-alkanes with chain lengths of $\mathrm{C}_{6}-\mathrm{C}_{16}$, but failed to grow with long chain alkanes of $\mathrm{C}_{20}-\mathrm{C}_{32}$. This degradation capability may be attributed to the genome encoded cytochrome P450, which catalyzes the hydroxylation of medium chain alkanes [26, 27]. We suspect that they can also oxidize short chain alkanes $\left(\mathrm{C}_{2}-\mathrm{C}_{4}\right)$ because the corresponding gene encoding $\mathrm{pHMO}$ was found in their genomes (data not shown). To the best of our knowledge, this is the first report of a SAR324 group delta-proteobacteria being capable of alkane degradation, which highlights their role in alkane oxidation in natural environments. Moreover, the success of a pure culture will help us gain insight into the metabolic mechanisms and environmental interactions of these organisms in global oceans.

Bacteria of the genus Sulfurimonas are commonly isolated from sulfidic habitats, and numerous 16S rRNA 
sequences related to Sulfurimonas have been identified in hydrothermal deep-sea vents, marine sediments, pelagic water columns, and terrestrial habitats [28]. Although Sulfurimonas species play important roles in chemoautotrophic processes in some habitats [28, 29], some species can grow with organic substrates, such as Sulfurimonas sp. CVO, and Sulfurimonas gotlandica can use acetate in addition to carbon dioxide and bicarbonate as a carbon source [30, 31]. Sulfurimonas denitrificans can grow with a formate, fumarate, yeast extract, and alcohol mix as electron donors, while $S$. gotlandica can grow with formate, acetate, yeast extract, pyruvate, and amino acid mix as electron donors [31]. In this study, four isolates of Sulfurimonas could all grow well with $\mathrm{C}_{6}-\mathrm{C}_{12} n$-alkanes as an electron donor and carbon source, and they were capable of degrading naphthalene. To the best of our knowledge, this is the first report of this genus being capable of utilizing hydrocarbons. In addition, these isolates can also oxidize reduced sulfur compounds. The versatility in mixotrophic metabolisms may explain the ubiquity of Sulfurimonas in the global hydrothermal vent biosphere. Mixotrophs in vent surroundings are probably common; therefore, investigations of other microbial taxa are needed.

There is very little information is available about the interactions of heterotrophic bacteria with hydrocarbons in deep-sea hydrothermal environments. Prior to this study, two mesophilic Proteobacteria, Salinisphaera hydrothermalis, and Parvibaculum hydrocarboniclasticum were isolated from deep-sea hydrothermal vents on the EPR and were capable of growth on $n$-alkanes as their sole carbon source [32, 33]. In addition, isolates of Alcanivorax and Marinobacter were recovered from hydrothermal environment samples of the $9^{\circ} \mathrm{N}$ EPR and the $37^{\circ} \mathrm{N}$ MAR [34]. However, their degradation capacity under in situ conditions remains untested. This study confirmed diverse heterotrophic bacteria inhabiting global deep-sea hydrothermal environments, possibly using hydrocarbon degradation as an energy source. By mimicking in situ conditions, we confirmed their capacity of active degradation of various hydrocarbons at HPs (2000-3500 m water depth) and low temperature. Marinobacter spp., Halomonas spp., and the SAR202 clade predominated bacterial communities in the hydrocarbon-degrading SIP consortia from the SMAR, SWIR, and EPR sulfide chimneys, respectively. Alcanivorax spp., Marinobacter spp., Cycloclasticus spp., and the SAR202 clade dominated the hydrocarbon-degrading SIP community of hydrothermal vent plumes. Erythrobacter spp., Alcanivorax spp., Halomonas spp., and the SAR202 clade were the most predominant members of the PAH-degrading consortia from all hydrothermal sediments, while Pusillimonas was the predominant genus in the SIP consortium from SWIR sediments at $49^{\circ} \mathrm{E}$ (S7). Notably, the above hydrocarbondegrading bacteria also occurred the dominant members of the indigenous bacterial community from hydrothermal samples, suggesting they interacted with vent effluents and surrounding environments by utilizing hydrocarbons generated from deep subspaces.

SAR202, which is a cluster of uncultured bacteria affiliated with the phylum Chloroflexi, are medium-sized, free-living heterotrophic organisms [35-38]. Even in sediments at the bottom of the Challenger Deep of the Mariana Trench, SAR202 is the dominant population of bacterial communities [39]. Recently, Landry and colleagues analyzed five single-amplified genomes of the SAR202 clade and found that they encoded several families of oxidative enzymes such as ring-hydroxylating and ring-cleavage dioxygenases, cytochrome $\mathrm{P} 450$ and monooxygenase, which were believed to participate in hydrocarbon degradation [40]. In the present study, the SAR202 clade comprised $1.0-3.5 \%$ of the total bacterial $16 \mathrm{~S}$ rRNA gene abundance in all tested samples. Further, bacteria of the SAR202 clade were the dominant population (about $6.0-14.5 \%)$ in all of the aforementioned hydrocarbondegrading SIP consortia. Remarkably, the SAR202 clade became the dominant member in all five sediment-derived PAHs enrichments from SMAR, SWIR, and EPR (Fig. S5). Although the hydrocarbon metabolism of the SAR202 clade is still unknown, our results indicated that the SAR202 clade can degrade hydrocarbons, especially PAHs, and they might play a role in the degradation of recalcitrant organic matter in deep-sea hydrothermal fields. However, the bacteria of the SAR202 group need further investigation to confirm their ability for hydrocarbon degradation with pure cultures, which have yet to be developed.

Among these heterotrophic bacteria, Pusillimonas and Erythrobacter are less often reported in hydrocarbon degradation. Indeed, this is the first report of Pusillimonas being capable of PAH degradation. The isolate Pusillimonas sp. S7-N8 from our sediment enrichments showed only $96.7 \%$ similarity of the 16S rRNA gene with that of

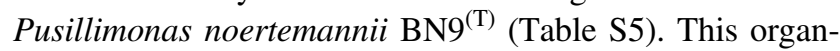
ism exhibited vigorous growth on alkanes and PAHs under high HPs and low temperature (Fig. S4). This is the first member of the genus Pusillimonas as a PAH-degrader. In the present study, Erythrobacter bacteria, which typically inhabit marine surface environments, were found to be are one of the predominant bacteria in vent plumes accounting for $6.6-8.5 \%$ of the total $16 \mathrm{~S}$ rRNA gene sequences. Intriguingly, the isolate of Erythrobacter showed a wide PAHs degradation range covering 2-5 fused rings, including naphthalene, phenanthrene, pyrene, fluorene, and benzo $[\alpha]$ pyrene. Moreover, the novel species from our enrichments, Erythrobacter atlantica sp. S21-N3 [41], could grow well on PAHs at $30 \mathrm{MPa}\left(5^{\circ} \mathrm{C}\right)$.

In summary, various hydrocarbons were found in global deep-sea hydrothermal environments, and they had a unique composition pattern in vent plumes compared to 
chimney sulfides and sediments. Correspondingly, various hydrocarbon-degrading bacteria were found in these hydrothermal samples. Interestingly, the chemoautotrophic bacteria clade SAR324 and Sulfurimonas were capable of degrading either alkanes and/or PAHs. In addition, heterotrophic bacteria belonging to the genus Alcanivorax, Cycloclasticus, Marinobacter, Halomonas, Pusillimonas, and Erythrobacter were found in situ as dominant members capable of hydrocarbon oxidation. The results of the present study demonstrate that the deep-sea hydrothermal vent ecosystem fosters unique mixotrophic bacteria, in addition to obligate heterotrophs and chemolithotrophs.

Acknowledgements This work was financially supported by the National Key Research and Development Program of China (Nos. 2018YFC0310701 and 2018YFC0310705), the Project of the National Science Foundation of China (41922041, 41876143, and 91851203), COMRA Program (No. DY135-B2-01), and the Natural Science Fund for Distinguished Young Scholars of Fujian Province of China (2017J06012).

Author contributions ZS and WW planned and managed the projects. WW and ZS designed the experiments. ZS and CD contributed to oceanic sampling. WW, ZL, and LZ conducted further experiments and analyzed the data. WW and ZS interpreted the results and wrote the manuscript.

\section{Compliance with ethical standards}

Conflict of interest The authors declare that they have no conflict of interest.

Publisher's note Springer Nature remains neutral with regard to jurisdictional claims in published maps and institutional affiliations.

Open Access This article is licensed under a Creative Commons Attribution 4.0 International License, which permits use, sharing, adaptation, distribution and reproduction in any medium or format, as long as you give appropriate credit to the original author(s) and the source, provide a link to the Creative Commons license, and indicate if changes were made. The images or other third party material in this article are included in the article's Creative Commons license, unless indicated otherwise in a credit line to the material. If material is not included in the article's Creative Commons license and your intended use is not permitted by statutory regulation or exceeds the permitted use, you will need to obtain permission directly from the copyright holder. To view a copy of this license, visit http://creativecommons. org/licenses/by/4.0/.

\section{References}

1. Konn C, Charlou J-L, Donval J-P, Holm N, Dehairs F, Bouillon S. Hydrocarbons and oxidized organic compounds in hydrothermal fluids from Rainbow and Lost City ultramafic-hosted vents. Chem Geol 2009;258:299-314.

2. Simoneit BR. Hydrothermal petroleum. In: Hydrocarbons, oils and lipids: diversity, origin, chemistry and fate. 2018. p. 1-35.

3. McCollom TM, Simoneit BR, Shock EL. Hydrous pyrolysis of polycyclic aromatic hydrocarbons and implications for the origin of PAH in hydrothermal petroleum. Energy Fuels 1999;13:401-10.
4. Didyk BM, Simoneit BR. Hydrothermal oil of Guaymas Basin and implications for petroleum formation mechanisms. Nature 1989;342:65

5. Preiner M, Xavier JC, Sousa FL, Zimorski V, Neubeck A, Lang SQ, et al. Serpentinization: connecting geochemistry, ancient metabolism and industrial hydrogenation. Life. 2018;8:41.

6. Wei J, Ge Q, Yao R, Wen Z, Fang C, Guo L, et al. Directly converting $\mathrm{CO}_{2}$ into a gasoline fuel. Nat Commun 2017;8:15174.

7. Konn C, Charlou JL, Holm NG, Mousis O. The production of methane, hydrogen, and organic compounds in ultramafic-hosted hydrothermal vents of the Mid-Atlantic Ridge. Astrobiology 2015;15:381-99.

8. Li J, Peng X, Zhou H, Li J, Chen S, Wu Z, et al. Characteristics and source of polycyclic aromatic hydrocarbons in the surface hydrothermal sediments from two hydrothermal fields of the Central Indian and Mid-Atlantic Ridges. Geochem J. 2012;46:31-43.

9. Delacour A, Früh-Green GL, Bernasconi SM, Schaeffer P, Kelley DS. Carbon geochemistry of serpentinites in the Lost City Hydrothermal System (30 N, MAR). Geochim Cosmochim Acta. 2008;72:3681-702.

10. Colman DR, Poudel S, Stamps BW, Boyd ES, Spear JR. The deep, hot biosphere: twenty-five years of retrospection. Proc Natl Acad Sci USA. 2017;114:6895-903.

11. Sheik CS, Jain S, Dick GJ. Metabolic flexibility of enigmatic SAR324 revealed through metagenomics and metatranscriptomics. Environ Microbiol 2014;16:304-17.

12. Li M, Jain S, Dick GJ. Genomic and transcriptomic resolution of organic matter utilization among deep-sea bacteria in Guaymas Basin hydrothermal plumes. Front Microbiol 2016;7:1125.

13. Li M, Jain S, Baker BJ, Taylor C, Dick GJ. Novel hydrocarbon monooxygenase genes in the metatranscriptome of a natural deepsea hydrocarbon plume. Environ Microbiol 2014;16:60-71.

14. Dick GJ, Anantharaman K, Baker BJ, Li M, Reed DC, Sheik CS. The microbiology of deep-sea hydrothermal vent plumes: ecological and biogeographic linkages to seafloor and water column habitats. Front Microbiol 2013;4:124.

15. Lesniewski RA, Jain S, Anantharaman K, Schloss PD, Dick GJ. The metatranscriptome of a deep-sea hydrothermal plume is dominated by water column methanotrophs and lithotrophs. ISME J 2012;6:2257-68.

16. Dombrowski N, Seitz KW, Teske AP, Baker BJ. Genomic insights into potential interdependencies in microbial hydrocarbon and nutrient cycling in hydrothermal sediments. Microbiome. 2017;5:106.

17. Wang Y, Feng X, Natarajan VP, Xiao X, Wang F. Diverse anaerobic methane- and multi-carbon alkane-metabolizing archaea coexist and show activity in Guaymas Basin hydrothermal sediment. Environ Microbiol 2019;21:1344-55.

18. Cui Z, Lai Q, Dong C, Shao Z. Biodiversity of polycyclic aromatic hydrocarbon-degrading bacteria from deep sea sediments of the Middle Atlantic Ridge. Environ Microbiol. 2008;10:2138-49.

19. Wang B, Lai Q, Cui Z, Tan T, Shao Z. A pyrene-degrading consortium from deep-sea sediment of the West Pacific and its key member Cycloclasticus sp. P1. Environ Microbiol 2008;10:1948-63.

20. Wang W, Wang L, Shao Z. Polycyclic aromatic hydrocarbon (PAH) degradation pathways of the obligate marine PAH degrader Cycloclasticus sp. strain P1. Appl Environ Microbiol. 2018;84: e01261-18.

21. Dong C, Bai X, Sheng H, Jiao L, Zhou H, Shao Z. Distribution of $\mathrm{PAHs}$ and the PAH-degrading bacteria in the deep-sea sediments of the high-latitude Arctic Ocean. Biogeosciences. 2015;12:2163-77.

22. Yuan J, Lai Q, Sun F, Zheng T, Shao Z. The diversity of PAHdegrading bacteria in a deep-sea water column above the Southwest Indian Ridge. Front Microbiol 2015;6:853. 
23. Shah V, Chang BX, Morris RM. Cultivation of a chemoautotroph from the SUP05 clade of marine bacteria that produces nitrite and consumes ammonium. ISME J 2017;11:263-71.

24. Mattes TE, Nunn BL, Marshall KT, Proskurowski G, Kelley DS, Kawka OE, et al. Sulfur oxidizers dominate carbon fixation at a biogeochemical hot spot in the dark ocean. ISME J 2013;7:2349-60.

25. Dick GJ, Tebo BM. Microbial diversity and biogeochemistry of the Guaymas Basin deep-sea hydrothermal plume. Environ Microbiol. 2010;12:1334-47.

26. Wang L, Wang W, Lai Q, Shao Z. Gene diversity of CYP153A and AlkB alkane hydroxylases in oil-degrading bacteria isolated from the Atlantic Ocean. Environ Microbiol. 2010;12:1230-42.

27. Liu C, Wang W, Wu Y, Zhou Z, Lai Q, Shao Z. Multiple alkane hydroxylase systems in a marine alkane degrader, Alcanivorax dieselolei B-5. Environ Microbiol. 2011;13:1168-78.

28. Han Y, Perner M. The globally widespread genus Sulfurimonas: versatile energy metabolisms and adaptations to redox clines. Front Microbiol 2015;6:989.

29. Meier DV, Bach W, Girguis PR, Gruber-Vodicka HR, Reeves EP, Richter M, et al. Heterotrophic Proteobacteria in the vicinity of diffuse hydrothermal venting. Environ Microbiol 2016;18:4348-68.

30. Gevertz D, Telang AJ, Voordouw G, Jenneman GE. Isolation and characterization of strains CVO and FWKO B, two novel nitratereducing, sulfide-oxidizing bacteria isolated from oil field brine. Appl Environ Microbiol. 2000;66:2491-501.

31. Labrenz M, Grote J, Mammitzsch K, Boschker HT, Laue M, Jost $\mathrm{G}$, et al. Sulfurimonas gotlandica sp. nov., a chemoautotrophic and psychrotolerant epsilonproteobacterium isolated from a pelagic redoxcline, and an emended description of the genus Sulfurimonas. Int J Syst Evol Microbiol. 2013;63:4141-8.

32. Crespo-Medina M, Chatziefthimiou A, Cruz-Matos R, PérezRodríguez I, Barkay T, Lutz RA, et al. Salinisphaera hydrothermalis sp. nov., a mesophilic, halotolerant, facultatively autotrophic, thiosulfate-oxidizing gammaproteobacterium from deepsea hydrothermal vents, and emended description of the genus Salinisphaera. Int J Syst Evol Microbiol. 2009;59:1497-503.
33. Rosario-Passapera R, Keddis R, Wong R, Lutz RA, Starovoytov V, Vetriani C. Parvibaculum hydrocarboniclasticum sp. nov., a mesophilic, alkane-oxidizing alphaproteobacterium isolated from a deep-sea hydrothermal vent on the East Pacific Rise. Int J Syst Evol Microbiol. 2012;62:2921-6.

34. Bertrand EM, Keddis R, Groves JT, Vetriani C, Austin RN. Identity and mechanisms of alkane-oxidizing metalloenzymes from deep-sea hydrothermal vents. Front Microbiol. 2013;4:109.

35. DeLong EF, Preston CM, Mincer T, Rich V, Hallam SJ, Frigaard NU, et al. Community genomics among stratified microbial assemblages in the ocean's interior. Science 2006;311: 496-503.

36. Schattenhofer M, Fuchs BM, Amann R, Zubkov MV, Tarran GA, Pernthaler J. Latitudinal distribution of prokaryotic picoplankton populations in the Atlantic Ocean. Environ Microbiol. 2009;11:2078-93.

37. Varela MM, van Aken HM, Herndl GJ. Abundance and activity of Chloroflexi-type SAR202 bacterioplankton in the meso- and bathypelagic waters of the (sub)tropical Atlantic. Environ Microbiol 2008;10:1903-11.

38. Mehrshad M, Rodriguez-Valera F, Amoozegar MA, Lopez-Garcia $\mathrm{P}$, Ghai R. The enigmatic SAR202 cluster up close: shedding light on a globally distributed dark ocean lineage involved in sulfur cycling. ISME J 2018;12:655-68.

39. Nunoura T, Nishizawa M, Hirai M, Shimamura S, Harnvoravongchai $\mathrm{P}$, Koide $\mathrm{O}$, et al. Microbial diversity in sediments from the bottom of the Challenger Deep, the Mariana Trench. Microbes Environ 2018;33:186-94.

40. Landry Z, Swan BK, Herndl GJ, Stepanauskas R, Giovannoni SJ. SAR202 genomes from the dark ocean predict pathways for the oxidation of recalcitrant dissolved organic matter. mBio. 2017;8: e00413-17.

41. Zhuang L, Liu Y, Wang L, Wang W, Shao Z. Erythrobacter atlanticus sp. nov., a bacterium from ocean sediment able to degrade polycyclic aromatic hydrocarbons. Int $\mathrm{J}$ Syst Evol Microbiol. 2015;65:3714-9. 